\title{
Decreasing Thermal Cracking on Asphalt Pavement by Nano Calcium Carbonate (CCN) Modified Bitumen
}

\author{
Javad Tanzadeh* and Atousa Kianfar \\ Islamic Azad University Science \& Research Branch, Iran \\ *tanzadeh@hotmail.com
}

\begin{abstract}
Thermal cracking is one of the serious damage of asphalt pavements that occurs in cold areas. Thermal stress extend with decreasing temperature in the surface layer of asphalt when it reaches to critical value cracks occur. In recent years Nano materials commonly use to improve performance in bitumen. In this paper, Nano calcium carbonate $(\mathrm{CCN})$ have been used to improve performance characteristics of bitumen at low temperature. For this purpose the bending beam remoter BBR test is carried out on unmodified and CCN-modified bitumen samples. $\mathrm{CCN}$ is added to control the bitumen at contents of $4 \%$ and $6 \%$ by the weight of bitumen and BBR test is done at $-6^{\circ} \mathrm{C}$ and $-12{ }^{\circ} \mathrm{C}$ temperatures. BBR use to measure stiffness of bitumen at low temperature. The results showed that using $\mathrm{CCN}$ in bitumen samples cause to improvement on performance characteristics of bitumen at low temperatures particularly at $-12{ }^{\circ} \mathrm{C}$ in comparison with unmodified bitumen samples. The results of BBR on samples modified with $\mathrm{CCN}$ is compared with previous research show on modified asphalt binder with Nano clay that the effect of CCN is better on performance characteristics of bitumen compared with Nano clay at low temperature.
\end{abstract}

Keywords: Bitumen, Thermal cracks, Creep stiffness, BBR, CCN.

\section{INTRODUCTION}

The rheological properties of asphalt mixtures are obtained from the bitumen components. The studies have shown that the behavior of the asphalt is such as a viscoelastic material (Yao et al, 2012). It have depended seriously on the temperature and time (Yao et al. 2013), So that the mixture behaves such as an elastic material at low temperature and viscous material at high temperature (You et al. 2011). Many researches have been accomplished to improve resistance and adhesion of bitumen (Khattak et al. 2013). It is received more attention to improve the performance of bitumen and asphalt mix to bear heavier loads and reduce the damage caused by the traffic and weather conditions. Based on the studies of Lei, most additives can improve resistance of the deformation bitumen at high temperatures, but it is less improvement on flexibility of bitumen at low temperatures (Lei, Bahia, Yi-qiu. 2015). So thermal cracks is a serious problem, especially in cold areas.
Therefore, improvement of cracks and stiffness characteristics of bitumen is important at the low temperature. In addition, Vural Kök'studies showed thermal cracks at low temperature are not related to applied load. They are created by thermal shrinkage due to cold environment (Vural Kok, Akpolat. 2015). Bending beam rheometer test (BBR) measures the stiffness of the bitumen at Low temperature by static load. Recently engineers have been used new materials to improve the mechanical properties of asphalt mix such as additives, due to the increasing traffic load, weather conditions and changes in environmental conditions (According to the project location). In 2012 researches of Yao demonstrated, additives such as Nano materials have the potential to improve the performance of bitumen and asphalt mix, as the use of these additives is increasing in order to improve asphalt mix. Since many studies have been done for improvement of bitumen and asphalt mixes using Nano materials. In 
2014, Shafabakhsh investigated the effect of Nano-Titanium dioxide ( $\mathrm{TiO} 2$ ) on improvement characteristics of bitumen and asphalt mix. In this study, Nano-titanium dioxide was added $1 \%, 3 \%, 5 \%$ and $7 \%$ by weight of bitumen. Some experiments are performed such as the degree of penetration, softening point and ductility rotational viscometer. Results showed that the optimal content of Nano-titanium dioxide was $5 \%$ by weight of bitumen. In addition, indirect tensile fatigue test was performed for samples of modified asphalt mixtures with the addition of $1 \%, 3 \%, 5 \%$ Nano-titanium dioxide by weight of bitumen and samples of unmodified asphalt mixtures too. Results of this research showed that samples of modified asphalt mixtures had creep performance better than samples of unmodified asphalt concrete mixtures (Shafabakhsh, Mirabdolazimi and Sadeghnejad. 2014). In 2013, Yao investigated the characteristics of modified bitumen by adding $4 \%$ and $6 \%$ of Nano-silica by the weight of bitumen. Based on the results of this research viscosity and complex shear modulus of modified bitumen decreased slightly compared to unmodified bitumen. Dynamic modulus of $6 \%$ Nano-silica modified asphalt mixture was higher $4 \%$ Nanosilica modified asphalt mixture (Yao et al. 2013). In this paper the effect of adding of Nano calcium carbonate is investigated to improve the performance characteristics of bitumen. Nano calcium carbonate is named CCN. For this purpose, BBR test was performed on unmodified and modified bitumen samples by two different content of CCN.

\section{ANALYSIS OF CRITICAL POINTS OF ASPHALT PAVEMENTS}

The main distresses of asphalt pavement associated with Low temperature cracks, Permanent deformations, Fatigue cracks (Yao et al. 2011). Low temperature cracking is a kind of thermal cracking, which occur in very low temperature and Lower temperature than the failure temperature of the asphalt mix. The ability to reduce stress decreases at low temperature and thermal stress caused by low temperature are higher than the tensile strength of the asphalt layer, then the failure of asphalt mix creates (Soenen, Vanelstraete. 2003).

Generally, According to studies conducted are defined thermal fatigue cracks and thermal cracks at critical points of asphalt pavement as follows:

1. Thermal cracks are caused by thermal stress over the tensile strength of asphalt mixtures. And these cracks are created in point lof the pavement surface from top to bottom.

2. While fatigue cracks are created by fatigue due to load at the bottom of asphalt layer (point 3) and they grow from the bottom to the top of asphalt layer. The location of the damage are shown in asphalt pavement in Figure 1. Critical points caused by the cracks has been shown on asphalt pavement in Figure 1.

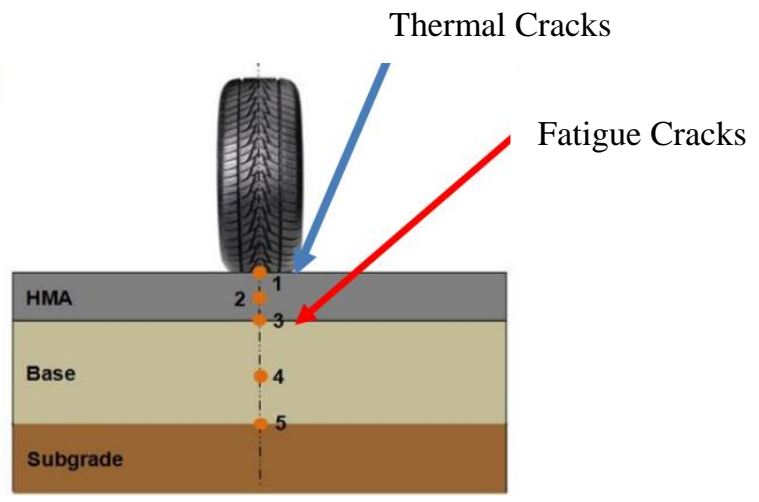

Figure 1: Location of thermal cracks and fatigue cracking 
Generally, asphalt have viscoelastic behavior at high temperature, so thermal stress caused by temperature drop depreciate through relaxtion stress. Also, it reduced tendency to cracking in the asphalt pavement. But at low temperature range asphalt have elastic behavior, so thermal stress caused by temperature drop would not be depreciate. Therefore if thermal stress is more than the tensile strength of the asphalt, cracking will be create. So limiting thermal cracks can be done one of two ways, according to the creep modulus and relaxtion modulus the material, as creep modulus and relaxtion modulus are key factors that have an impact on thermal cracks.
Limiting creep modulus of materials:

$S_{(t)}=1 / D_{(t)}, \quad D_{(t)}=\varepsilon_{(t)} / \sigma_{0} \neq 1 / E_{(t)}$

Higher relaxtion modulus of materials:

$\mathrm{E}(\mathrm{t})=\sigma(\mathrm{t}) / \varepsilon 0, \quad \mathrm{D}(\mathrm{t}) \neq 1 / \mathrm{E}(\mathrm{t})$

\section{MATERIALS DECREASES}

\subsection{Bitumen}

The bitumen AC $60 / 70$ (penetration grade of bitumen 60-70) used for this study and was obtained from the Tehran Oil Refining Co. The properties of used bitumen are shown in Table 1.

Table 1: Characteristics of the bitumen used in this study

\begin{tabular}{|c|c|}
\hline Property & Value \\
\hline Softening point $\left(\mathrm{C}^{\circ}\right)$ & 50.2 \\
\hline $\begin{array}{c}\text { Penetration grade } \\
\text { in25 } \mathrm{C}^{\circ}\end{array}$ & 63 \\
\hline${\text { Flash Point }\left(\mathrm{C}^{\circ}\right)}^{\text {Ductility in } \mathrm{C}^{\circ} 25}$ & 234 \\
\hline $\begin{array}{c}(\mathrm{cm}) \\
\text { Density }\left(\mathrm{g} / \mathrm{cm}^{3}\right)\end{array}$ & $>110$ \\
\hline Permeability index & -0.6 \\
\hline
\end{tabular}

\subsection{Nano Calcium Carbonate (CNN)}

In this study was used Nano calcium carbonate to improve the performance characteristics of bitumen at low temperatures. $\mathrm{CCN}$ was manufactured by the American Company Elements. CNN was white color and had high melting point. The average particle size was about $80-10 \mathrm{~nm}$. Some features of $\mathrm{CCN}$ are shown in Table 2. Image of Nano calcium carbonate $(\mathrm{CCN})$ is taken by an electron microscope and it is shown in Figure 2.

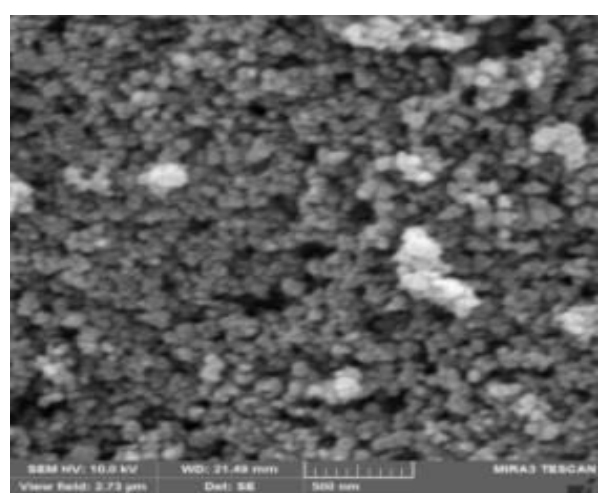

Figure 2: Images of scanning microscopy of Nano calcium carbonate 
Table 2: Characteristics of nano calcium carbonate used in this study

\begin{tabular}{|c|c|}
\hline Property & Value \\
\hline Molecular Weight & 100.9 \\
\hline Appearance & White Powder \\
\hline Melting Point & $825^{\circ} \mathrm{C}$ \\
\hline Boiling Point & Decomposes \\
\hline Density & N/A \\
\hline True Density & $2.93 \mathrm{~g} / \mathrm{cm}^{3}$ \\
\hline Bulk Density & $0.68 \mathrm{~g} / \mathrm{ml}^{3}$ \\
\hline Average Particle Size & $10-80 \mathrm{~nm}$ \\
\hline Size Range & $\mathrm{N} / \mathrm{A}$ \\
\hline Crystal Phase & N/A \\
\hline Morphology & cubic or hexagona \\
\hline
\end{tabular}

\section{TESTING AND ANALYSIS}

According to previous subjects, Nano-calcium carbonate is added to bitumen to evaluate the improvement of performance characteristics of bitumen at low temperatures. To have this aim, BBR test is done and three types of bitumen beam is made including unmodified bitumen beam and two type of modified bitumen beam by $\mathrm{CCN}$. Pure bitumen is modified by adding of $4 \%$ and $6 \% \mathrm{CCN}$ in high shear mixer during 15 minutes and $2000 \mathrm{rpm}$. Rolling thin film vessel (RTFO) test is examined in Temperature $163^{\circ} \mathrm{C}$ in 85 minutes. And then to perform pressure aging vessel (PAV) test, long term aging test, have been examined at 20 hours of at the high temperature $110^{\circ} \mathrm{C}$.

\subsection{Bending Beam Rheometer test (BBR)}

Bitumen behavior is determined under static load at low temperature by BBR test. BBR test is a Performance test. In addition, it is according to materials resistance equations. BBR test was performed according to AASHTOT313 for bitumen aged by RTFO and PAV tests. Bitumen beam had $12.7 \mathrm{~cm}$ length, $1.25 \mathrm{~cm}$ width and $0.625 \mathrm{~cm}$ thickness (Figure 3). The test beams were placed under a constant $980 \mathrm{mN}$ load in the fluid bath for 4 minutes. The average of the three replicate tests used to the analyze. The Creep stiffness (S) and m-value are important parameters is obtained from BBR test. The resistance of bitumen adhesive material is stated by the Creep stiffness ( $\mathrm{S})$, and the m-value is the slope curve of the logarithm Creep stiffness versus logarithm time at any time and its value must be greater than or equal to 0.3 within 60 seconds.

The equation used to calculate the creep stiffness is According to equation 5.

Deflection of an elastic beam

Where $\mathrm{I}=\mathrm{bh}^{3} / 12$

Elastic flexural modulus

Maximum bending stress

Maximum bending strain

Linear viscoelastic stiffness modulus:

Where $\mathrm{P}=$ constant load $(\mathrm{N}), \mathrm{L}=$ span length $(102 \mathrm{~mm}), \mathrm{b}=$ width of beam $(12.5 \mathrm{~mm})$, And $\mathrm{h}=$ thickness of beam $(25.6 \mathrm{~mm}), \delta(\mathrm{t})=$ deflection of beam $(\mathrm{mm})$.

$$
\begin{aligned}
& \delta=\mathrm{PL}^{3} / 48 \mathrm{EI} \\
& \mathrm{E}=\mathrm{PL}^{3} / 4 \mathrm{bh}^{3} \delta \\
& \sigma=3 \mathrm{pl} / 2 \mathrm{bh}^{2} \\
& \varepsilon=6 \delta \mathrm{h} / \mathrm{L}^{2} \mathrm{~mm} / \mathrm{mm}
\end{aligned}
$$$$
\mathrm{S}=\mathrm{PL}^{3} / 4 \mathrm{bh} \mathrm{h}^{3} \delta(\mathrm{t})
$$ 


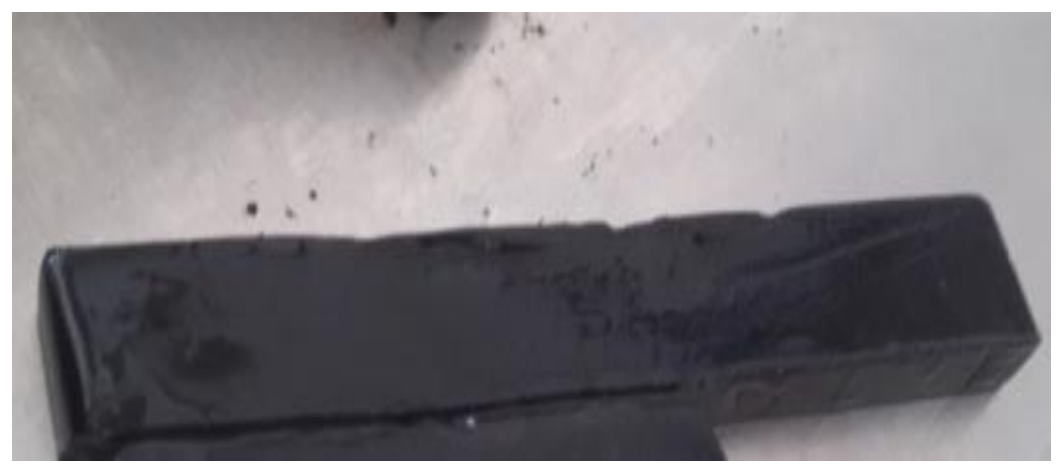

Figure 3: Sample of Modified bitumen by nano calcium carbonate in BBR test

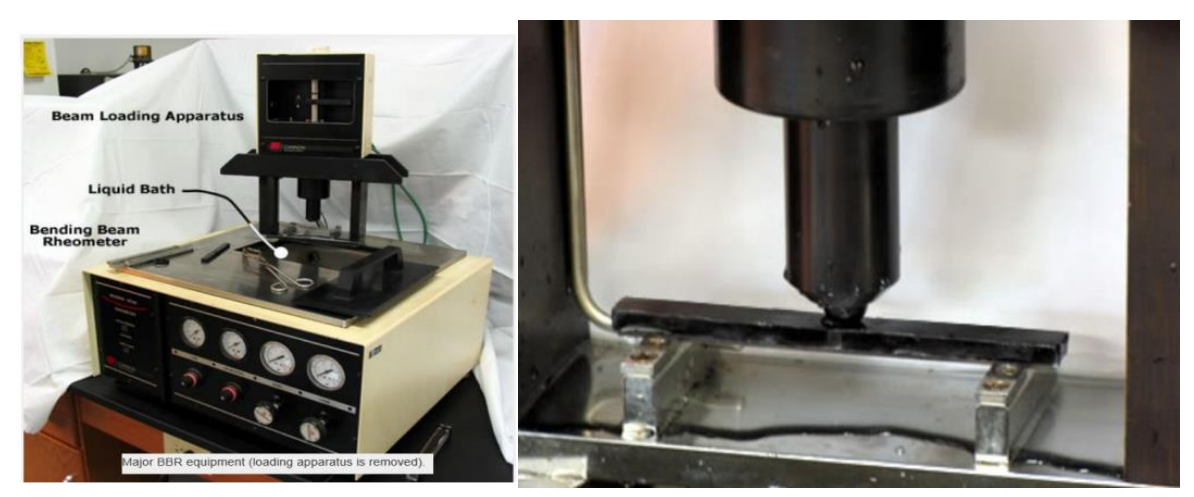

Figure 4: Bending beam rheometer

\subsection{The Analysis of Experimental Results}

Creep stiffness determines asphalt mix stiffness specifications and the crack resistance of asphalt pavements at low temperature, so low stiffness of bitumen can decrease stress in the asphalt mix at low temperature and reduce possibility of thermal cracks. Chart of creep stiffness has been shown for unmodified bitumen and modified bitumen by $4 \%$ and $6 \%$ of Nano calcium carbonate in Figures 5 and 6.

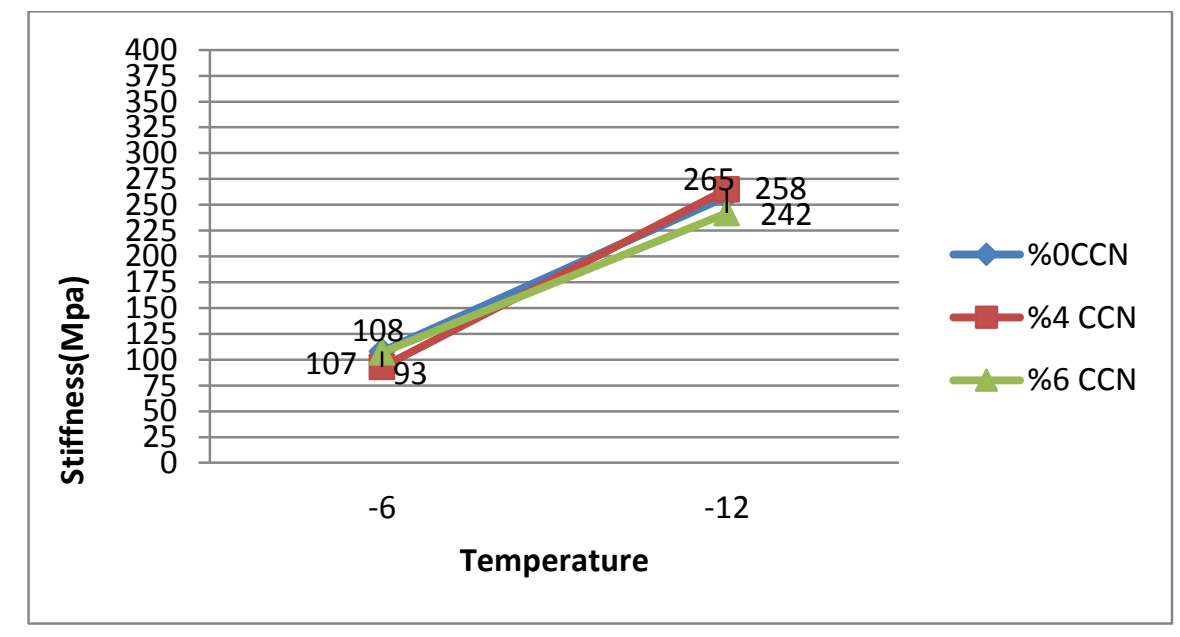

Figure 5: The Effect of CCN in Creep Stiffness of Bitumen 


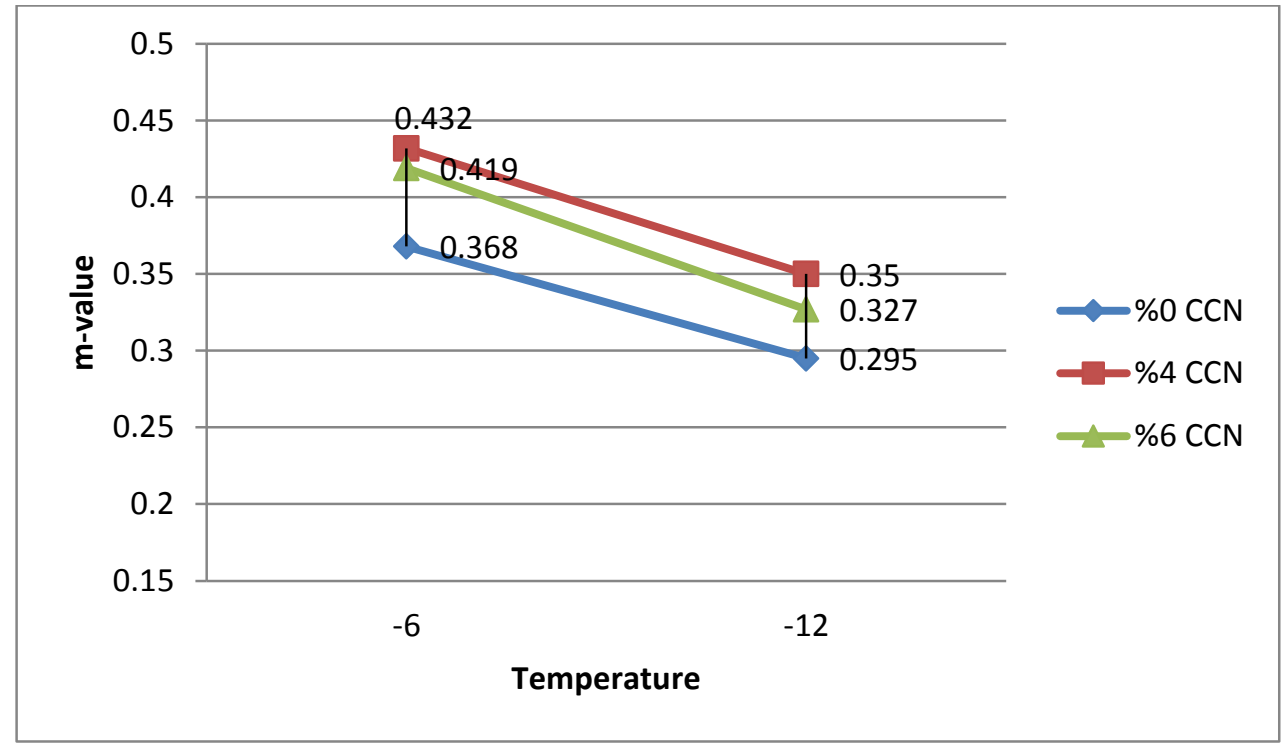

Figure 6: The effect of $\mathrm{CCN}$ in $\mathrm{m}$-value

The study results had shown that performance low-temperature bitumen was not improved for Samples of modified bitumen with the addition of 2 and $4 \%$ Nano clay compared to samples of unmodified bitumen, as unmodified bitumen samples have been their low temperature performance and the relaxation stress better than samples of modified bitumen by Nano clay.

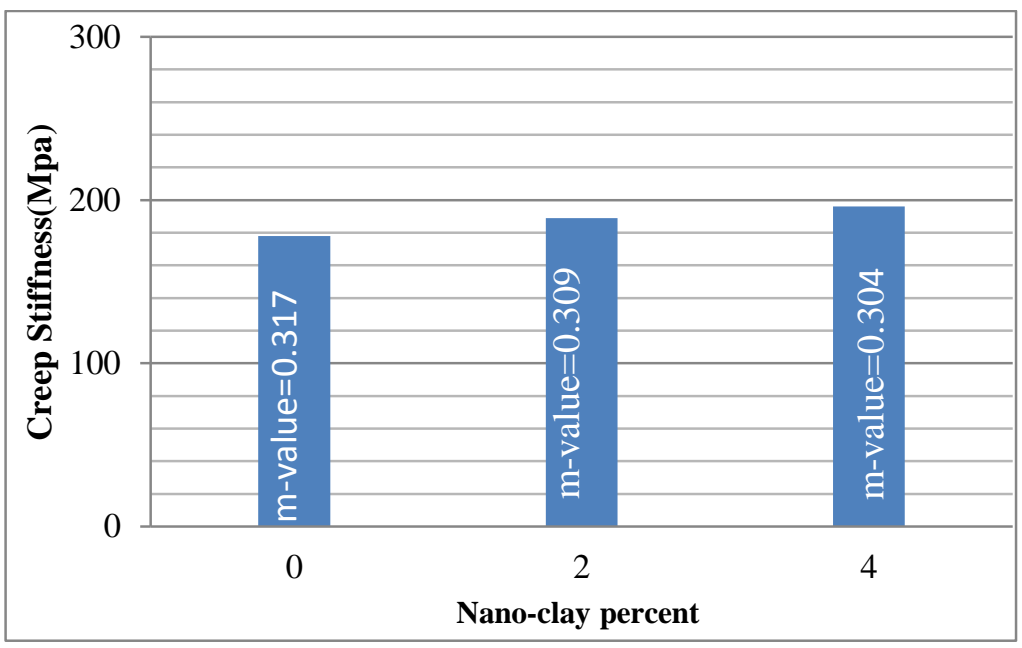

Figure 7: Creep Stiffness Result of Control And Nano-Caly Modified Bitumen At A Temperature Of $-14^{\circ} \mathrm{c}$ By Nano-Caly

\section{RESULT}

Adding $\mathrm{CCN}$ to bitumen has caused bitumen resistance increasing against temperature decrease. When critical temperature of unmodified bitumen samples is -6 o $\mathrm{C}$, by adding $\mathrm{CCN}$ to bitumen critical temperature have more decrease and become from $-6 \mathrm{oC}$ to -
$12 \mathrm{oC}$ and -18 oC. In compared with the Nano clay can be concluded that the changes of stiffness of bitumen versus time during loading by adding $\mathrm{CCN}$ is more than Nano clay. Also, bitumen resistance has been most effect on reducing the critical temperature and increasing 
stiffness of bitumen by adding $4 \% \mathrm{CCN}$. While, its effect on increasing of creep stiffness is reduced in compare to further reduction of temperature by adding the content of $6 \% \mathrm{CCN}$ by weight of bitumen. On the other hand, increasing $\mathrm{CCN}$ amount at low temperature have low impact on creep stiffness of bitumen. It should be noted that creep stiffness caused by BBR test can not completely demonstrate the capability of pulling the bitumen before failure. For example, some of bitumen with high creep stiffness can also stretch farther before breaking. So the amount of bitumen strain is measured before breaking with direct tensile test at very low temperatures. If the bitumen have suitable ductility at low temperature, high creep stiffness will occur. So direct tensile test must performed for the bitumen with creep stiffness between 300 and $600 \mathrm{MPa}$. If creep stiffness of bitumen is less than $300 \mathrm{MPa}$, there will not be necessary to perform direct tensile test.

\section{REFERENCES}

Khattak, M. J., Khattab, A., Zhang , P., Rizvi , H. R., \& Pesacreta, T. (2013). Microstructure and fracture morphology of carbon nano-fiber modified asphalt and hot mix asphalt mixtures. Materials and Structures, 46(12):2045-2057.

Lei, Zh., Bahia, H., Yi-qiu, T . (2015). Effect of bio-based and refined waste oil modifiers on low temerature performance of asphalt. Construction and Building Materials , 86: 95-100.

Shafabakhsh, Gh., Mirabdolazimi, S.M., Sadeghnejad, M. (2014). Evaluation the effect of nano-TiO2on the rutting and fatigue behavior of asphalt mixtures. Construction and Building Materials , 54: 566-571.

Soenen, H., Vanelstraete, A. (2003). Performance indicators for low temperature cracking. Sixth International RILEM Symposium on Performance Testing and Evaluation of Bituminous Materials. 458-464
Vural Kok, B., Akpolat, M. (2015). Effects of Using Sasobit and SBS on the Engineering Properties of Bitumen and Stone Mastic Asphalt . Journal of Materials in Civil Engineering, 27(10)

Yao, H.,You, Zh., Li, L., Shi, X., Goh, S.W., Mills-Beale, J., Wingard, D . (2012). Performance of asphalt binder blended with non-modified and polymermodifiednanoclay. Construction and Building Materials, 35: 159-170.

Yao, H., You, Zh., Li, L., Lee, C.H., Wingard, D., Yap, Y.K., Shi, X., Goh, S.W. (2013). Rheological properties and chemical bonding of asphalt modified nanosilica. Journal of Materials in Civil Engineering, 25(11):1619-1630.

You, Zh., Mills-Beale, J., Fini, E., Goh, S.W., Colbert, B. (2011). Evaluation of lowtemperature binder properties of warmmix asphalt, extracted and recovered RAP and RAS, and bioasphalt. Journal of Materials in Civil Engineering, 23(SPECIAL ISSUE: Energy Efficient and Environmentally Friendly Paving Materials):1569-1574. 